University of Nebraska - Lincoln

DigitalCommons@University of Nebraska - Lincoln

\title{
Numerical and Experimental Investigation of Vascular Suture Closure
}

\author{
Linxia Gu \\ University of Nebraska-Lincoln, gul@fit.edu \\ Ananth Ram Mahanth Kasavajhala \\ University of Nebraska-Lincoln, arm13888@gmail.com \\ Haili Lang \\ University of Nebraska Medical Center, haililang@unmc.edu \\ James M. Hammel \\ University of Nebraska Medical Center, jmhammel@unmc.edu
}

Follow this and additional works at: https://digitalcommons.unl.edu/mechengfacpub

Part of the Biomedical Engineering and Bioengineering Commons, and the Mechanical Engineering Commons

Gu, Linxia; Kasavajhala, Ananth Ram Mahanth; Lang, Haili; and Hammel, James M., "Numerical and Experimental Investigation of Vascular Suture Closure" (2012). Mechanical \& Materials Engineering Faculty Publications. 79.

https://digitalcommons.unl.edu/mechengfacpub/79

This Article is brought to you for free and open access by the Mechanical \& Materials Engineering, Department of at DigitalCommons@University of Nebraska - Lincoln. It has been accepted for inclusion in Mechanical \& Materials Engineering Faculty Publications by an authorized administrator of DigitalCommons@University of Nebraska Lincoln. 


\title{
Numerical and Experimental Investigation of Vascular Suture Closure
}

\author{
Linxia Gu, ${ }^{1,2}$ Ananth Ram Mahanth Kasavajhala, ${ }^{1}$ Haili Lang, ${ }^{3}$ and James M. Hammel ${ }^{3}$
}

\author{
1. Department of Mechanical and Materials Engineering, University of Nebraska-Lincoln, Lincoln, NE 68588-0656 \\ 2. Nebraska Center for Materials and Nanoscience, Lincoln, NE 68588-0656 \\ 3. Department of Surgery, University of Nebraska Medical Center, Omaha, NE 68114 \\ Corresponding author - Linxia Gu, tel 402 472-7680, fax 402 4721465, email lgu2@unl.edu
}

\begin{abstract}
Purpose - In order to optimize the performance of the suture for tissue closure, it is essential to develop strategies for devising new and improved techniques that can visualize and compare various suturing techniques. This paper describes an experimental and numerical investigation on the performance of sutured tissue.

Methods - In the experiments, two pieces of glutaraldehyde cross-linked bovine pericardium were sutured together through simple running suture and tensioned to study the performance of the sutured tissue. During testing, the tension load and the total displacement of the specimen were recorded. The strain field of the specimen was simultaneously captured using two high speed cameras and post processed using its associated image processing software. In addition, nonlinear hyperelastic material models for Shelhigh patch and cryopreserved human aorta were derived through least-square fitting into the tensile testing data. Three dimensional finite element models were developed to replicate the behavior of wound closure.

Results - The effect of tissue material mismatch, and stiffness of the suture thread on the mechanical behavior of sutured tissue was examined. The stain distributions obtained from simulation agrees with the captured surface strain map from experiments. A relative softer suture thread could reduce the peak stress concentrations at the knotting location.

Conclusions - The mechanical performance of sutured tissue depends on the level of mismatch in material stiffness between the native tissue and the replacement material
\end{abstract}

Keywords: Surgical suture test, Optical surface strain measurement, Tissue anastomosis, Finite element modeling, Material mismatch

\section{Introduction}

Suturing has long been the standard procedure for vascular tissue repair and replacement to restore the physical integrity and function of the injured or diseased tissue. Suture failures are rare but the consequences may be disastrous [1]. Massive bleeding, thrombosis, wound dehiscence, or anastomotic stenosis may occur. Numerous clinical studies of wound closure with sutures have looked into the biological causes and remedies of complications at the suture line, including healing characteristics, types of suture techniques and direction of the incision [1-3]. Lowenberg and Shumacker [2] observed that while the force necessary to break recently sutured artery by direct pull was as little as 2 lbs., the sutured artery rapidly regained resistance to mechanical loadings
(6 lbs.) after 14 days or longer. It is speculated that tissue material mismatch, physiological loading level, and suture thread selection have caused considerable strains on the sutured tissue, which might have led to the complications and failure of the suture. In order to optimize the performance of the suture for tissue closure, it is essential to develop strategies for devising new and improved techniques that can visualize and compare various suturing techniques.

Finite element method (FEM) has been proven to be a useful and efficient tool for pre- as well as post-surgical simulation, including suture modeling [4]. Initial investigations mainly focused on developing a sensible model to mimic the suturing task of a skin lesion. In fact, the application of FEM in understanding the technicalities involved in the wound closure mechanism was 


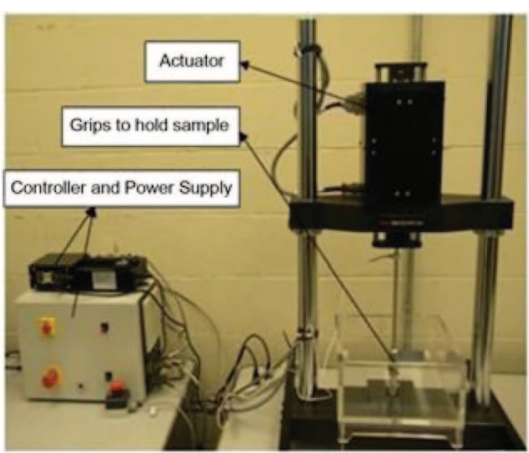

a

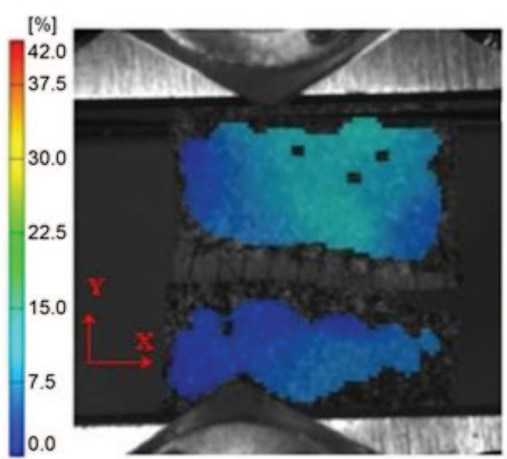

b

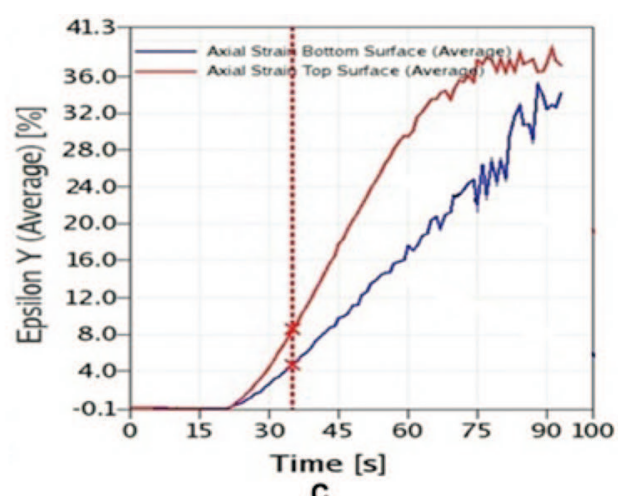

Figure 1. (a) Tensile test system; (b) Averaged surface strain in Y direction on the sutured tissue obtained from ARAMIS surface strain measurement system; and (c) Averaged Y strain over the surfaces of top and bottom tissues.

first pioneered by DeHoff et al. in early 1980s, wherein they used two-dimensional FE models to determine the forces necessary for closing a wound [5]. Berkley et al. developed a suturing simulator to mimic tissue deformations during suturing skin lesions [6, 7]. Recently, Liu et al. carried out experimental and FE analysis on endtoend anastomosis and proposed a force range of $0.05 \mathrm{~N}$ to $0.4 \mathrm{~N}$ for suture tension during tightening within which, there won't be any blood osmosis or tissue ripping [8]. A similar computational study conducted by Al-Sukhun et al. on the vascular stress field of micro vascular anastomosis, compared end-to-end and end-to-side vessel geometry mismatch [9]. They found out that end-to-side suturing is more effective in reducing stress in the vessel wall. Yoshida et al. analyzed skin sutures using three dimensional FE models to predict the degree of extrusion post suturing and concluded that there is $40 \%$ reduction in the degree of extrusion using a modified S-shaped suture method [10,11]. A similar study of post suture effects of tissue stresses performed by Chaudhry et al. revealed that stresses in the tissue increased considerably with the increase in suture density $[12,13]$. However, in the documented suture studies, simple linear elastic material was generally adopted for the soft tissue, and two dimensional models were used to simulate the suturing task $[4,9,12,13]$. More complex nonlinear material models of tissues and the effect of material mismatch are needed before models can realistically represent the physiological environments.

In this work, both experimental and numerical methods were used to better understand the performance of sutured tissue. Two pieces of glutaraldehyde fixed pericardium were sutured together using a $0.7 \mathrm{~mm}$ monofilament polypropylene suture thread. Uniaxial tensile tests were performed and the mechanical behavior of sutured tissue was evaluated through a high speed CCD imaging system. Experimentally obtained strain maps of the sutured tissue surface were used to validate the developed three dimensional FE models. Nonlinear material properties of the commercially available peri- cardial patch and aortic tissue were measured and the fitted material coefficients were implemented into our computational models. The effect of tissue material mismatch and stiffness of the suture thread on the mechanical behavior of the joint was evaluated without considering the effect of residual stresses in the tissue before or after suturing.

\section{Materials and Method}

\section{Specimens}

For material assessment, a patch of glutaraldehyde crosslinked bovine pericardium (Shelhigh No-React, Shelhigh, Union, NJ) and aortic wall tissue from a $10 \mathrm{~mm}$ diameter cryopreserved human aortic root (CryoLife, Inc., Kennesaw, GA) have been considered. The pericardial patch and aorta were dissected to $11.1 \times 5.26 \mathrm{~mm}$ and $11.1 \times$ $4.42 \mathrm{~mm}$ along longitudinal and transverse directions respectively. For the suture test setup, pericardial patch with an average thickness of $0.55 \mathrm{~mm}$ was cut into two square segments of length $11.17 \mathrm{~mm}$ which are connected by a $0.7 \mathrm{~mm}$ diameter polypropylene suture thread (Prolene ${ }^{\circledR}$ 6-0, Ethicon $8805 \mathrm{H}$ ) using a simple running suture technique. All the substrates were then stored in saline/antibiotic bath at $2^{\circ} \mathrm{C}$ for $7 \mathrm{hrs}$, before testing, to reduce dehydration and decay of the tissue.

\section{Testing methods}

Uniaxial tensile tests were carried out using TestResources 800LM250Q tissue tensile testing machine with a $20 \mathrm{~N}$ load cell (Figure 1a). Specimens were mounted onto top and bottom tissue grips. The top grip, connected to the load cell, was initially adjusted to reach a zero stress state. All the tests were performed using displacement control with a ramping rate of $0.05 \mathrm{~mm} /$ sec. Force and displacement data were recorded at a frequency of $20 \mathrm{~Hz}$. Then the nominal stress and strain were calculated based on the recorded original dimensions (the cross-section and gauge length). 
In addition, the local strains on the specimen surface were captured during the tension test and measured using the ARAMIS 3D strain measurement system (Trillion Optical Test Systems, PA). The system uses two high speed optical cameras to take pictures at 15 FPS, of a random contrasting pattern of paint sprayed on the tissue surface to construct accurate measurements of motion of each point. This enables the ARAMIS system to calculate the strain at each point and thereby average it over the surface to obtain surface strain map at every frame using digital image correlation (DIC) software (Figure $1 b$ ).

The strain map corresponding to the top and bottom tissue surfaces was obtained at every instance of deformation until the tissues were torn apart. It is clear from Figure $1 \mathrm{~b}$ that the local strain distribution is non-uniform over the surface of the specimen. As such, the averaged nominal strain along $\mathrm{Y}$ direction measured on the top and bottom tissue surface varied as shown in Figure 1c. This may be explained by the non-uniform material properties of the tissue and the asymmetrical suturing. The dotted vertical line at around 35 second corresponds to the physiological pressure range around 0.1 to $0.2 \mathrm{MPa}$.

\section{Constitutive models of tissues}

Biological tissues are more appropriately represented by the J-Shape hyperelastic constitutive models instead of linear elastic material models. Strain energy density function (ABAQUS Version 6.10 Online documentation, SIMULIA Inc) in the form of a second order reduced polynomial has been used to describe the nonlinear constitutive relationship of pericardial patch and the aorta tissue as shown below.

$$
U=C_{10}\left(I_{1}-3\right)+C_{20}\left(I_{2}-3\right)^{2}
$$

Where $U$ is the strain energy per unit of volume, $C_{10}$ and $C_{20}$ are material coefficients fitted from the experiment data, $I_{1}$ and $I_{2}$ are the first and second invariants of the Cauchy- Green tensor, respectively:

$$
I_{1}=\frac{\lambda_{U}^{3}+2}{\lambda_{U}} \quad \text { and } \quad I_{2}=\frac{1+2 \lambda_{U}^{3}}{\lambda_{U}^{2}}
$$

The principal stretch $\lambda_{U}=1+\varepsilon_{U^{\prime}}$ and $\varepsilon_{U}$ is the nominal strain from uniaxial tension tests. The uniaxial nominal stress could be derived as

$$
\sigma_{U}=2\left(\begin{array}{c}
\lambda_{U}^{3}-1 \\
\lambda_{U}^{3}
\end{array}\right)\left[C_{10} \lambda_{U}+2 C_{20}\left(\lambda_{U}^{3}-3 \lambda_{U}+2\right)\right]
$$

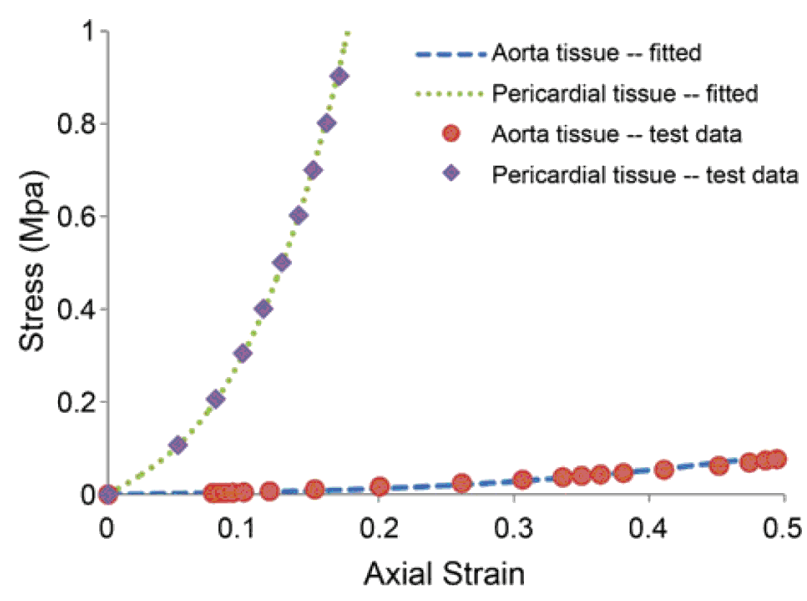

Figure 2. Mechanical behavior of tissues fitted with test data.

The test data and the fitted constitutive equations are plotted in the Figure 2. The obtained material coefficients are listed in Table 1. It is evident that the aortic tissue is much softer than pericardial patch. The stiffness of suture is more than 1000 times higher than the pericardial patch. The stiffness mismatch may play an important role in the effectiveness of the whole anastomosis process. Lai et al. [15] indicated that the choice of suture size, material and technique depends on the tension of the tissue being sutured. For example, a lower stiffness suture thread for a high wound tension would rather tear the tissue.

\section{Computational Modeling}

Three dimensional models of sutured tissues were developed to mimic the uniaxial tension experiment as shown in Figure 1. Each piece of tissue has a length of $11.17 \mathrm{~mm}$, width of $11.17 \mathrm{~mm}$, and thickness of $0.55 \mathrm{~mm}$ with nine holes of $0.7 \mathrm{~mm}$ diameter to accommodate the suture thread. A solid model of suture thread, $0.7 \mathrm{~mm}$ in diameter with zigzag pattern resembling a running suture, was created using SolidWorks (Dassault Systèmes SolidWorks Corp., Vélizy, France) as shown in Figure 3. An optimal distance of $3.5 \mathrm{~mm}$ along y-direction proposed by Lai et al. (2010) between the holes in two pieces of tissue was adopted in the model with the overlap being $1 \mathrm{~mm}$. The tissue models were meshed using 8-noded linear hexahedral solid elements with an average aspect ratio of 1.38 while, the suture thread was

Table 1. Material properties of tissues and suture thread used.

\begin{tabular}{cc}
\hline Name & Material Properties \\
\hline Cryopreserved human aortic tissue & $C_{10}=0.005799999, C_{20}=0.03028611$ \\
Glutaraldehyde cross-linked bovine pericardial patch & $C_{10}=0.142959446, C_{20}=5.31890687$ \\
0.7 mm polypropylene monofilament suture ${ }^{[14]}$ & $\mathrm{E}=6240 \mathrm{MPa}, v=0.2$ \\
\hline
\end{tabular}




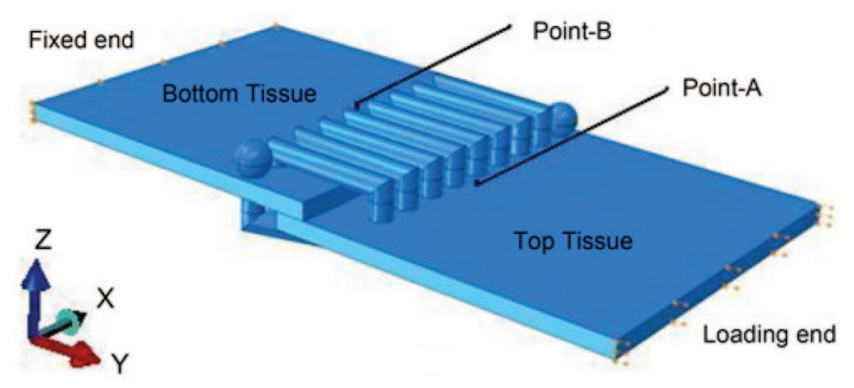

Figure 3. End-to-end suturing configuration.

meshed using 4-noded linear tetrahedron elements with an average aspect ratio of 2 using ABAQUS (Dassault Systémes Simulia Corp., RI, USA). Surface to surface contact with finite sliding with a coefficient of friction of 0.25 was specified in between the tissues and suture. The trailing end of the bottom tissue is fixed in all degrees of freedom while the trailing end of top tissue is loaded up to the physiological pressure range.

\section{Results and Discussions}

\section{Validation of the FE model}

The linearly increased displacement with a displacement rate of $0.05 \mathrm{~mm} / \mathrm{s}$ in the experiment is implemented in the FE models, wherein the maximum displacement is $6.68 \mathrm{~mm}$. The obtained averaged strain profile from the simulation is compared with the experimental ARAMIS result, as shown in the Figure 4a. The $Y$ strain data for both top and the bottom tissues were compared with respect to the applied displacement. There is $20 \%$ variance for the top tissue and 29\% difference observed in the bottom tissue. The disparity may be explained by the inconsistent surface area used to calculate the strain average. During tests, the averaged surface region is calculated based on varied areas depending on the visibility of reference points from ARAMIS output. However the strain in the simulation is based on a fixed area. It is clear that the strain will match better if we change the averaged area to two specific points A and B (Figure 3) on the tissue surface as specified in Figure $4 \mathrm{~b}$.

\section{Effect of tissue mismatch}

It is common practice to connect different tissues in a surgery. Therefore, in this study, the aortic tissue was sutured end to end to the pericardial patch, to investigate the effect of material mismatch. Figure 5 depicts that the aortic tissue underwent larger deformation and caused larger strain concentrations than the pericardial patch. This is due to the fact that the aortic tissue material is much softer than the pericardial patch. Compared to the applied load of $0.15 \mathrm{MPa}$, the difference in the peak max principal strain between the two tissues is $55.2 \%$ whereas, the max principal stress in the
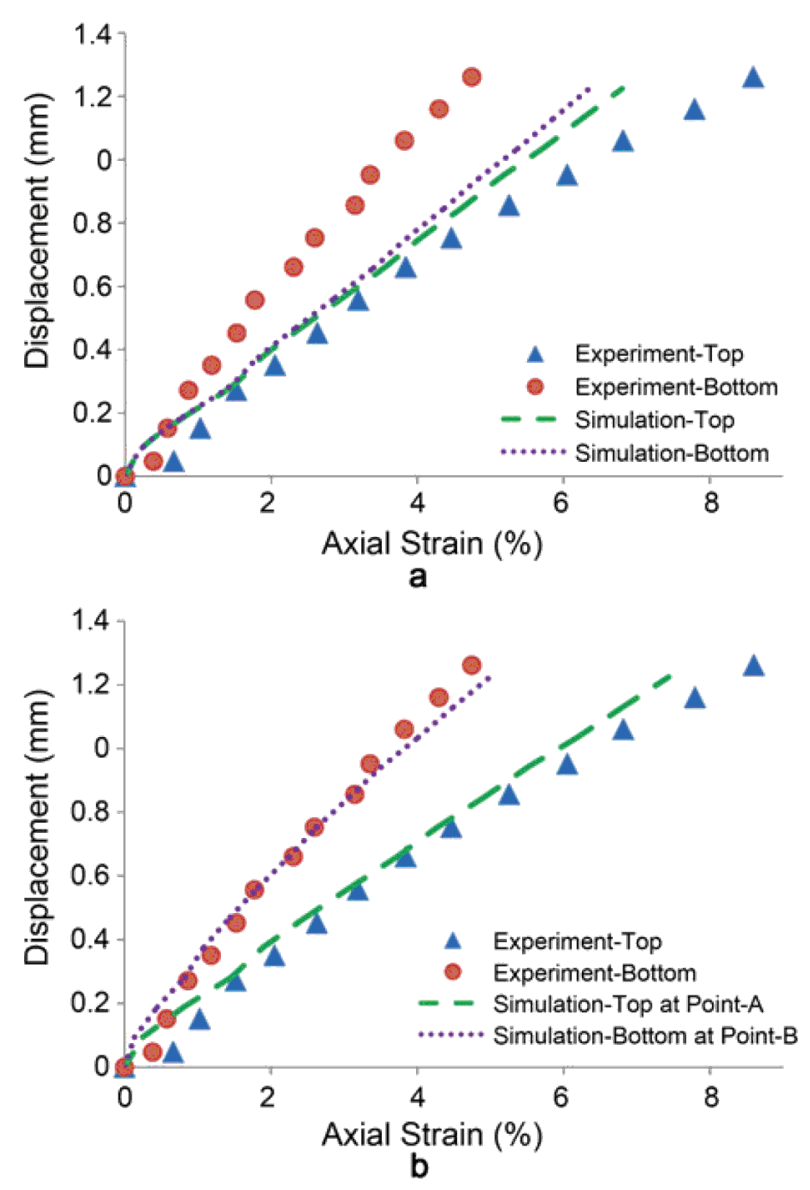

Figure 4. Comparisons of computationally obtained axial strains taken (a) averaged over surface and (b) at specified points with the ARAMIS results.

aortic tissue is $1.345 \mathrm{MPa}$ and $1.299 \mathrm{MPa}$ in the pericardial patch. The peak stress concentration in the aortic tissue is located at the edge of suture hole, which agrees with our observation during tensile test of the sutured tissue. This may be explained by the relative large distance between the suture hole and the edge of the tissue, which cause the large deformation around the closest suture hole.

Figure 6 demonstrated increased compliance when both sutured materials are the aortic tissue with a 0.7 $\mathrm{mm}$ suture thread. Under the same applied loading of $0.15 \mathrm{MPa}$, the overall displacement of the two tissues is $6.037 \mathrm{~mm}$ for the mismatched model and $10.72 \mathrm{~mm}$ for the same material suturing model. Under the same displacement of $6.02 \mathrm{~mm}$, the peak principle stresses for the same material model is reduced to $0.3686 \mathrm{MPa}$, compared to $1.345 \mathrm{MPa}$ for mismatch model. This may lead to the failure of mismatched sutured tissues prior to that of the same materials.

The relationship between applied load and the resulting displacement measured at the moving end of the sutured tissue is demonstrated in Figure 7. It is clear the pericardial patch suture assembly is much stiffer than 


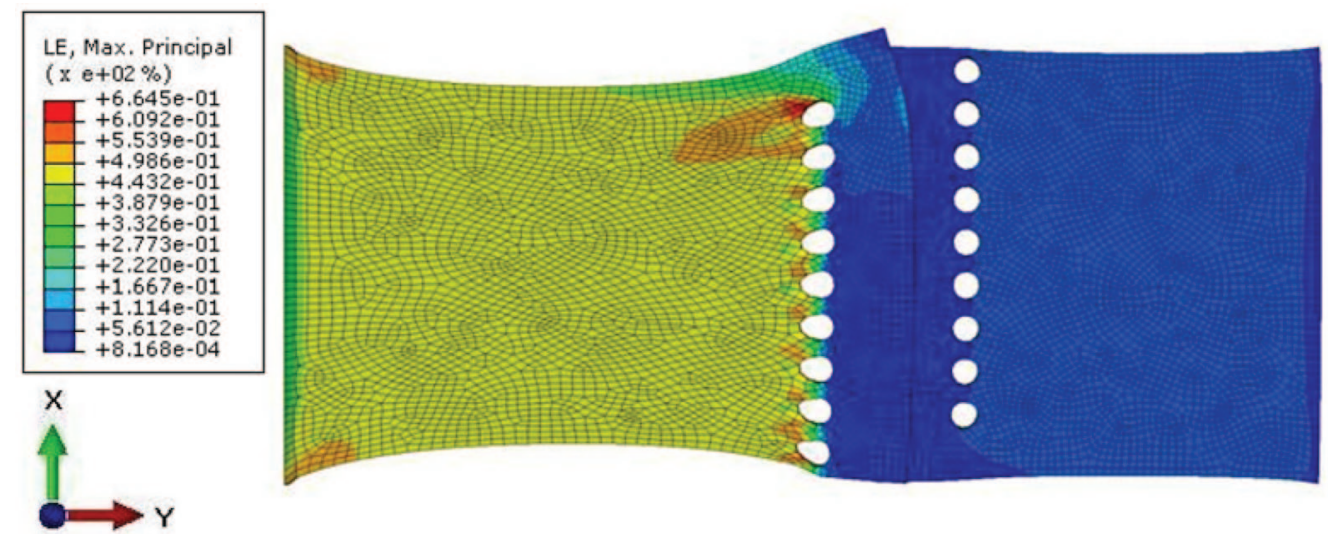

Figure 5. Max Principal Strain distribution in the cryopreserved human aorta tissue (left) and Shelhigh patch (right) under axial pressure of $0.15 \mathrm{MPa}$.
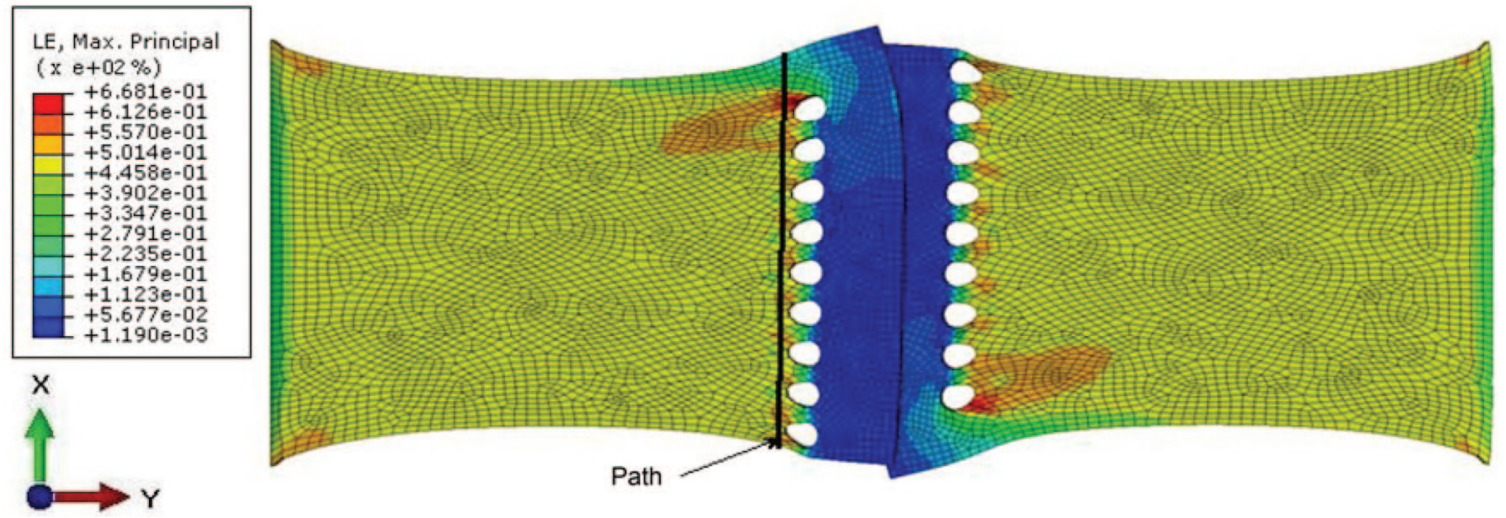

Figure 6. Variation of Max Principal Strain in cryopreserved human aorta tissues using 0.7mm suture.

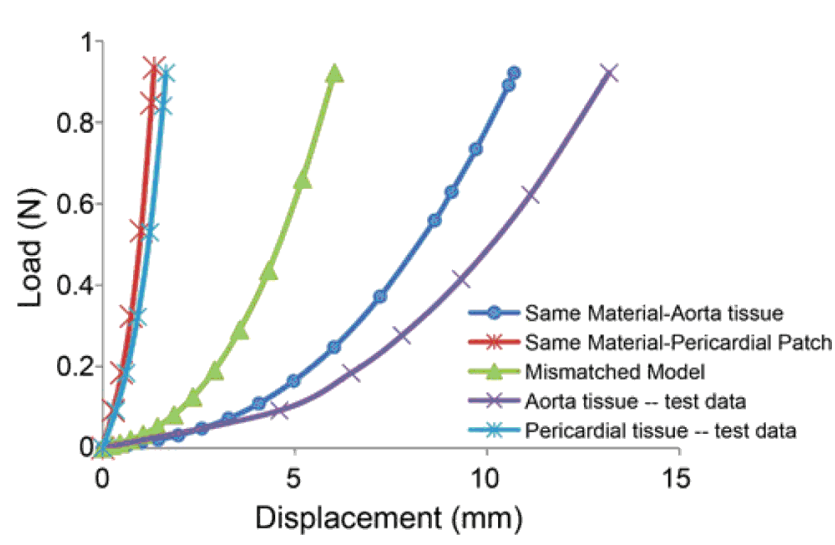

Figure 7. Load vs. displacement relationship for the suture assembly.

the aortic tissue suture assembly, and the mismatch suture assembly possesses the stiffness somewhere between the two. This indicates that a graft material with similar material properties as the native tissue will reduce the variation of mechanical environment after the repair. This agrees with the clinical observations [11].

\section{Effect of suture thread stiffness}

The influence of suture thread stiffness on the tissue

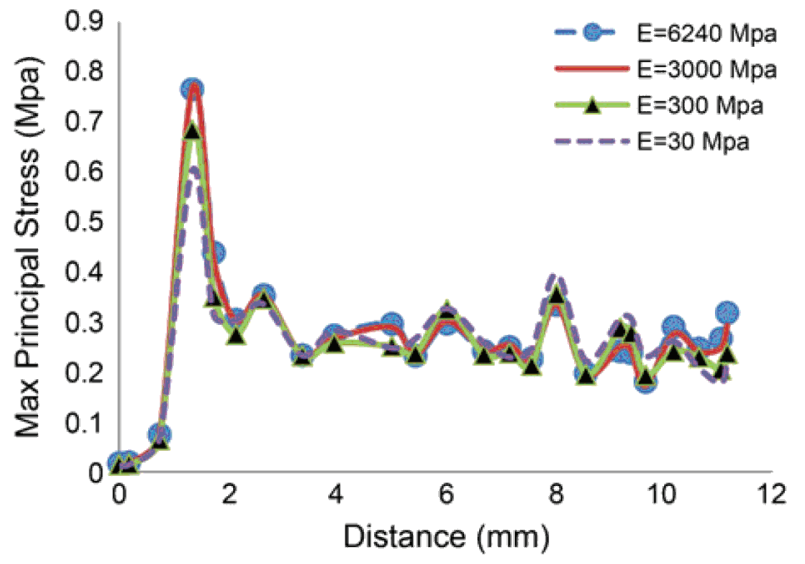

Figure 8. Influence of suture thread stiffness on the tissue.

stress is depicted in Figure 8. A wide range of material stiffness i.e., $6240 \mathrm{MPa}$ to $30 \mathrm{MPa}$ have been considered to study the effect of suture thread degradation, on the stress state in the tissue. It shows the maximum principle stress along the path specified in Figure 6. The peak stress around the corner holes other than the thread knot reduced along with a compliant thread. The variation of principle stress is very small away from the corner hole. This indicates a stiffer thread may introduce 
high stress concentration at the corner holes other than knotting location and little impact on the tissue away from the corner holes.

\section{Conclusions}

Experimental tests as well as three dimensional finite element simulations were conducted on end-to-end sutured tissue. The effect of suture thread stiffness and tissue mismatch has been studied. The following conclusions were deduced:

- Nonlinear hyperelastic material models for both glutaraldehyde cross-linked bovine pericardial patch and cryopreserved human aortic tissue were derived through least-square fitting into the tensile testing data

- The performance of sutured pericardial patch was evaluated through both tensile test and finite element modeling. The stain map obtained from simulation agrees with the captured surface strain through ARAMIS system

- The mechanical performance of sutured tissue depends on the level of mismatch in material stiffness between the native tissue and the replacement material

- The peak stress concentration at the knotting location is the critical area for damage initiation and this agrees well with the experiment. A relative softer suture thread could reduce this peak stress concentration

\section{Future Work}

The experimental and computational results show the effect of tissue mismatch on the stress state. However, the following concerns need to be considered for the prospective studies.

- Firstly, nonlinear material anisotropy for all the three layers of an artery

- Secondly, considering the influence of residual stresses in the soft tissue before suturing

Acknowledgments - The authors are grateful for funding from the National Science Foundation under grant No. 0926880. The authors also thank Mr. Shijia Zhao for helping with the tensile tests, Biomechanics, Biomaterials and Biomedicine Instrumentation Facility $\left(\mathrm{BM}^{3}\right)$ for providing the ARAMIS system with high speed cameras and Mr. Jonathan Hein for helping with ARAMIS system.

\section{References}

[1] Pourdeyhimi B, Wanger D. On the correlation between the failure of vascular grafts and their structural and material properties: A critical analysis. J Biomed Mater Res. 1986; 20:375-409.

[2] Lowenberg RI, Shumacker HBJ. Experimental studies in vascular repair Strength of arteries repaired by end-toend suture, with some notes on growth of anastomoses in young animals. Arch Surg. 1949; 59:74-83.

[3] Samaha F, Olive A, Buncke G, Buncke HJ, Siko PP. A clinical study of end-to-end versus end-to-side techniques for micro vascular anastomosis. Plast Reconstr Surg. 1997; 99:1109-11.

[4] LeDuc M, Payandeh S, Dill J. Toward modeling of a suturing task. Graph Interface. 2003. 273-9.

[5] DeHoff PH, Key JE. Application of the finite element analysis to determine forces and stresses in wound closing. J Biomech. 1981; 14:549-54.

[6] Berkley J, Turkiyyah G, Berg D, Ganter G, Weghorst S. Real-Time Finite Element Modeling for Surgery Simulation: An Application to Virtual Suturing. IEEE T Vis Comput Gr. 2004; 10:314-25.

[7] Berkley J, Weghorst S, Gladstone H, Raugi G, Berg D, Ganter M. Banded matrix approach to finite element modeling for soft tissue simulation. Virt Reality 1999; 4:203-12.

[8] Liu Y, Wang S, Jack HS, Qiu W. Mechanical analysis of end-to-end silk-sutured anastomosis for robot-assisted surgery. Int J Med Robot Comput Assist Surg. 2009; 5:444-51.

[9] Al-Sukhun J, Lindqvist C, Ashammakhi N, Penttil H. Micro vascular stress analysis Part I: Simulation of micro vascular anastomoses using finite element analysis. Brit J Oral Max Surg. 2007; 45:130-7.

[10] Yoshida H, Tsutsumi S, Mizunuma M, Yanai A. A surgical simulation system of skin sutures using a three-dimensional finite element method. Clin Biomech. 2001; 16:621-6.

[11] Yoshida H, Tsutsumi S, Mizunuma M, Yanai A. Threedimensional finite element analysis of skin suture Part 1: Spindle model and S-shaped modified model. Med Eng Phys. 2000; 22:481-5.

[12] Chaudhry HR, Bukiet B, Siegel M, Findley T, Ritter AB, Guzelsu N. Optimal patterns for suturing wounds. J Biomech. 1998; 31:653-62.

[13] Lott-Crumpler DA, Chaudhry HR. Optimal patterns for suturing wounds of complex shapes to foster healing. J Biomech. 2001; 34:51-8.

[14] Chu CC. Mechanical properties of suture materials: An important characterization. Ann Surg. 1981; 193:365-71.

[15] Lai YS, Becker GD, Edlich FR. Sutures and needles. eMedicine. WebMD, March 31, 2001; Online: http:/ / emedicine. medscape.com/article/884838-overview 